\title{
A comment prompted by Andy Williamson's "A review of New Zealand's digital strategy"
}

\author{
Garth Graham \\ Victoria, BC CANADA \\ <garth.graham@telus.net>
}

Editors' note: In December 2005, Garth Graham wrote the following "Comment" to accompany an article in our "Notes from the Field" by Andy Williamson (A Review of New Zealand's Digital Strategy. The Journal of Community Informatics, (2005) Vol. 2, Issue 1, pp. 71-75. http://ci-journal.net/index.php/ciej/article/view/263/221). In the midst of the software upgrade, it was lost until recently. When we asked Garth if he still wanted to publish it, with or without an update, he said:

"I still like it as a "community networking perspective" on such strategies. I was predicting what would be areas of difficulty for the strategy's implementation related to it's stated "community" intentions. Obviously, this was "in theory," since I've no idea what it feels like to be a New Zealander! I've had no involvement in New Zealand's two years of implementation experience, and it would take that to understand how the questions I raised are playing out. However, I notice from the NZ Strategy web site, that members of the ciresearchers list are actually members of the Strategy's National Advisory Board. Why not ask them?"

We did that, and in an email, August 20, 2007, here is how Andy Williamson responded:

"This is a very good discussion not least because it is in many ways eerily accurate. I wrote the original piece long before we actually ever did anything, in the early days of the strategy. Since then we have had some considerable successes but it is also true that we have missed some opportunities. I laughed a little at the comments on governance, I think we are now at a point where the advisory group has 'clout' but it was not I suspect the intent - as you guessed! I also liked the point about involving communities. I had hoped for and actively argued for a more grounded, community centric approach. I think the advisory group has had some success in this area but not enough and the process remains too government centric in all aspects of its implementation and management."

"As a contribution to the debate, I think it would be excellent to publish it and - perhaps with a caveat noting when it was written to avoid any criticism of it being out of date - time has marched on in one or two areas."

Andy asks us to note that, although he is currently Deputy Chair of the NZ Digital Strategy Advisory Group, the views expressed are his own.

Andy Williamson expressed the hope that New Zealand's new Digital Strategy (NZDS) represents an opportunity for the practices of community informatics to play a greater role in public policy for development. As someone from away, I am painfully aware that context is everything, and that the context for public participation in New Zealand's policy debate is unknown to me. So I shall try to follow his optimistic lead, and not come between public policy consultants and the governments they must seek to influence. However, I am more suspicious of the intentions of governmentbased digital strategies than Williamson.

The main problem I have is that neither the NZDS nor Williamson give me any sense of where the New Zealand focus for community informatics as a practice, or community-based communications initiatives, resides, or even if there is such a focus. And yet, it seems to me that the success of the NZDS will depend on the degree to which policies largely internal to government reflect a consensus that has been reached, or may be reached, in the public sphere. My question then becomes - who gets to tell the story of community networking in New Zealand?

Maybe the goals of the Strategy grew out of a dialogue with and among communities and the communities agree those are the goals. But this is not evident from the NZDS itself.

To the degree that the NZDS does represent an opportunity for community informatics to shine, what needs to occur in order to grasp that opportunity? To the degree that it does not, what can be done to bring the implications of the absence of a community informatics point-of-view into New Zealand's public policy debate?

Here's the pro side of that opportunity: 
- This is a national strategy that has, in fact, set itself up to actually learn what daily life in a knowledge society, mediated by broadband connectivity, will be like.

- "Community" is actually recognized as one of the "critical agents of change." This does make the NZDS an important experiment. And, yes, that acknowledgement of the role of community in a knowledge society may be a world first.

- Although imagined as a key technology component of a national productivity initiative, the goals are societal, rather than sectoral or primarily economic, and therefore horizontal in their implications.

- Not mentioned in the NZDS, but flowing from its implementation, there are two Government funds, the Broadband Challenge and the Community ICT Partnership, that support an "open access" network model, and do so in stated competition with New Zealand's prime communications carrier.

- The NZDS states, "Communities themselves are best placed to determine their own needs, in partnership with local government and other organizations. .... To be effective, initiatives must come from communities themselves. "(NZDS p. 33-34). This is good stuff!

Here's the con side:

- The Digital Strategy Advisory Board terms of reference are unclear but likely weak. Rather than open public dialogue grounded in the Advisory Group, it looks as if the "Steering Group" of senior bureaucrats has firm control of the processes of engaging with stakeholders, thus ensuring that the Ministers are not surprised politically. A true knowledge society would be more transparent.

- The NZDS is paternalistic or, more kindly, pessimistic in its expectations for citizens' embrace. The Strategy assumes that citizens have certain deficiencies that only governments can serve to alleviate. Its intended actions describe a search for "solutions" to problems (lack of information, lack of skills, lack of access to ICTs) that are identified and imposed from above. In other words, the key drivers for evoking community initiatives are assumed to be external to the community.

- Maori inclusion is placed in the context of "content." This risks the appearance of appropriation of culture as a commodity. It is a good idea to remember that concepts of property are artifacts of culture and not the reverse. However, I am reliably informed that the Maori are just as capable as anyone else of strategically leveraging off the NZDS to gain from any possible advantages it may have for them, and that they probably will.

- While the open access model calls for aggregation of all local authorities, the potential of using national government ICT procurement as an instrument for leveraging policy change towards open access networks doesn't seem to be anticipated.

- "Connection" means broadband technology or "infrastructure," not the interactive linking of people to people.

So, at the high level of political goals, it would seem that the opportunity to apply community informatics is real. But, at the implementation or public administration level, there is just the faintest whiff of the "Yes Minister" syndrome. Maybe we could label that technocratic avoidance of risk? The antidote to that avoidance is, of course, ongoing and open public debate about development goals and intentions, and about the NZDS's effectiveness in realizing them.

The heart and soul of community development lies in the autonomy of the individual to make choices about the future. The NZDS Summary states, "We can use the power of technology to connect people to the things that matter most to them." (p. 3). That "to connect people to" is bothersome. The pronoun "we" in that sentence implies that the connectors and the people are somehow separate and that connection is externally supplied, not self-determined.

What about the person who is changing or being changed? Good digital strategy depends on what we imagine we will be when we become digital. In terms of the NZDS, it seems as if we will:

- Have greater access to information as if that were a commodity rather than an aspect of the process of learning or a means to inform ourselves.

- Increase our use of ICTs because we will have been "made more confident" and that this is something we can and should do and that we will not be harmed in the process. We are going to be persuaded (a form of marketing) as to the benefits.

- Accept that "connection" as "access to affordable, high speed networking" is an "infrastructure" problem, not something to do with human communications and relationships.

- Act differently as consumers in the use of government services rather than interact as citizens.

The person imagined as the target of the NZDS seems strangely like the worker who got socialized and mobilized for productive behaviour in the industrial society. I'd guess however, that the e-people aren't going to behave that way.

In daily life online, the functions of governance are distributed across autonomous and self-organizing networks. And those networks are dynamic. A digital strategy for governance online cannot function if its implementers imagine that 
some sort of separation exists between suppliers of government (as services) and consumers of those services.

There is a big difference between a knowledge society grounded in knowing what and who it is, and a society grounded in the attempt to package something called "information" as a commodity or "service." New Zealand may find that, through the use of self-referencing feedback loops, a knowledge society informs and structures (or "governs") the interactions of social networks differently than the NZDS anticipates.

But, if they do, then they will be way ahead of the rest of us who aren't setting ourselves up to encounter and learn from that possibility head-on.

The idea of a knowledge society as the key to increased economic productivity is seductive for nation states. The idea of a knowledge society as change in the fundamental structures of governance is not usually embraced with the same enthusiasm. However the success of New Zealand (or of any nation state) in becoming such a society resides in the degree to which it accepts both inevitabilities.

In a democracy, public administrators know they can decentralize to a municipality without fear of loss of control, because a municipality has no powers except those granted to it in law. If they haven't been told they can do something, they must assume they cannot. But "community" is not a legal entity. For community, as it is for individuals, the law is, "That which is not stated is not implied."

In the absence of specific authorization or prohibition, a community is free to act, whereas a local government is not. The balancing of local autonomy and central power in a knowledge society is not delegated downward. The governors of the shape of networks are self referential, self-organizing and distributed. In a knowledge society, we should expect that communities online will emerge and that, as with corporate entities, they will behave as if they were citizens.

Public administrators know what they do well now in hanging on to power. They follow the practices of incrementalism and administrative delay. They also pay lip service to the notion of anything "community-based." In framing the NZDS, its authors seem to be saying, "There are things you lack. We will give them to you and you will become more productive in this new socio-economic context." In my own country Canada, when the givers of government grants arrive in community, they frequently find that community hasn't waited for their arrival in order to innovate, especially in bending the terms of the grant to apply it to their real needs.

Because local government is close to the ground where community emerges, I suspect the sleeper in this, the intended "supporting action" to watch most closely, is the unfunded "E-local government strategic plan" (NZDS p. 49). That plan is a component of the "transforming government" section. To leverage success through that particular component, it will be necessary to connect it with the open access model and to work with local governments to increase their awareness of the need to defend the Internet as a public utility and a public good. As being online pushes the nation state towards the non-linear, increasingly the fine-scale texture of the nation, observed more clearly through its local governments, will affect its large-scale behaviour.

Currently, the Federal Government of Canada does not have a strategy as comprehensive as New Zealand's. What national strategy Canada has is closely focused on the "ICT sector" as a question of industrial capacity and competitiveness. But there is a governance model in play in the province of British Columbia that might bear useful exchange of views, given the comprehensive policy framework that New Zealand has defined.

In learning and applying the practices of implementing broadband networks in rural and remote communities, the First Nations Technology Council and the BC Community Connectivity Cooperative (BC3) just co-exist informally, with significant overlapping membership, and with those pesky things organized as "partnerships" left to specific community-based projects. The Government of BC, through NetWork BC and its Digital Divide Strategy, actively supports what is, in essence, a resilient grassroots understanding of how to implement and operate broadband networks so as to enhance local control of development choices.

Now if only BC had been as brave as New Zealand in challenging the evolution of its own prime telecommunications carrier towards open access.

Will the NZDS work? Because of that open access model, probably yes. When it gets to where it's going, will it meet the intentions implied by its initial goals? Probably not as anticipated. But New Zealand does seem well set to discover just how much more than "access ", can be open. The success of the NZDS will depend on the degree to which evolving public policy debate in New Zealand anticipates what daily life in a knowledge society, mediated by broadband connectivity, will be like.

December 29, 2005 